\title{
Olfactory Discrimination of Mouse Strains (Mus musculus) and Major Histocompatibility Types by Humans (Homo sapiens)
}

\author{
Avery Nelson Gilbert, Kunio Yamazaki, and Gary K. Beauchamp \\ Monell Chemical Senses Center \\ Lewis Thomas \\ Memorial Sloan-Kettering Cancer Center
}

\begin{abstract}
A series of experiments revealed that humans can use olfaction to discriminate closely related strains of mice, differing genetically only at the major histocompatibility gene complex $(H-2)$. In Experiment 1, subjects were asked to distinguish between the whole-body odors of live mice. In Experiments 2 and 3, the odor source was mouse fecal pellets, and in Experiments 4 and 5, the odor source was mouse urine.
\end{abstract}

How well can people discriminate nonhuman odors of mammalian origin?

This question arises frequently, often in the course of invidious comparisons of the perceptual acuity of human and nonhuman mammals. There is, however, a more substantial question on which it bears, namely, the role of olfaction in animal social behavior and the extent to which exchange of information in the olfactory modality constitutes an evolved system of communication. One test by which a system is judged to serve a communicatory function is the criterion of formalization (Smith, 1977). Is the signal sent specific to the sender or the sender's context? Does the intended receiver possess a specialized receptive apparatus? The criterion of specificity holds for intraspecific communication (e.g., alarm pheromones) as well as for interspecific communication (e.g., plant-pollinator interactions). The criterion is based on evolutionary considerations: the need to minimize confusion among signals and the need to limit information parasitism. The human capacity to discriminate nonhuman mammalian odors is closely allied with the criterion of formalization, and thus we return to our original question.

As with so many issues in olfaction, myths, intuitions, and anecdotes abound, but rigorous treatment is difficult to find (but see Doty \& Dunbar, 1974). As a first step toward answering this question, we have made use of mouse strains differing only in the major histocompatibility complex of genes on chromosome 17 (Boyse, 1977). These genes, which among other things regulate immunologic function, have been mapped with some precision (Klein, 1982). Mice differing

This research was supported in part by National Institutes of Health [NIH] Postdoctoral Fellowship 5 F32 NS07353-02 to A. Gilbert and NIH Grant 9R01-GMCA-32096-04 to K. Yamazaki. Preliminary experiments were reported April 6. 1984, in Sarasota. Florida, at the meeting of the Association for Chemoreception Sciences.

We thank Nancy Sweitzer and Jean Fridorich for their assistance with experiments described here.

Correspondence concerning this article should be addressed to Avery Nelson Gilbert, Monell Chemical Senses Center, 3500 Market Street. Philadelphia. Pennsylvania 19104. genetically only in $H-2$ type produce different odors, and successful behavioral assays and training paradigms have been based on the scent of the mice themselves and of their urine (Yamaguchi et al., 1981, 1979). In the five experiments presented here, we asked whether the olfactory differences apparent to the mice are also accessible to humans.

\section{Experiment 1}

We first asked whether humans can discriminate the wholebody odor of live mice from closely related strains. The two inbred strains used as odor sources in this experiment (C57BL/6 and C57BL/6- $H-2^{\mathrm{k}}$ ) are congenic for $\mathrm{H}-2$; that is, they share the same background genotype, and they differ genetically only at the major histocompatibility complex (Boyse, 1977). The C57BL/6 strain is homozygous for the $\mathrm{H}$ 2 allele designated $b$; the C $57 \mathrm{BL} / 6-H-2^{\mathrm{k}}$ strain is homozygous for the $k$ allele.

\section{Method}

In all the experiments reported here, every animal was fed the same commercial mouse chow in order to avoid dietary-based differences in odor production. In addition, all mice werc housed under uniform conditions in the same animal room, and all were reproductively mature, that is, more than 3 months old. The human subjects were male and female adults.

In Experiment 1, five male mice each from C57BL/6 and C57BL/ $6-H-2^{k}$ strains were used as odor sources. The mice were placed individually in $10 \times 10 \times 6 \mathrm{~cm}$ plastic boxes with paired slots $(0.7 \times$ $7 \mathrm{~cm}$ ) cut into two sides. The animals were placed in the boxes 20 $30 \mathrm{~min}$ before testing.

Mice were presented successively in all 25 pairwise strain combinations. Seven blindfolded subjects were asked to smell the contents of each pair of boxes (one in each hand) and to indicate which "smelled stronger." The choice of "strength" as a stimulus dimension was based on pilot work suggesting that this was an adequate parameter. Subjects could sniff as often and as long as they wished.

The score for each subject was the number of times the more frequently chosen strain was labeled "stronger smelling." The maximum possible score of 25 indicates perfect discrimination of the two strains. The probability of scoring 18 or higher is less than .05 . 


\section{Results and Discussion}

Five of the seven subjects discriminated C57BL/6 mice from $\mathrm{C} 57 \mathrm{BL} / 6-H-2^{\mathrm{k}}$ mice at a statistically significant level (Table 1). Of these subjects, 3 rated $H-2^{\mathrm{k}}$ animals ( $k k$ homozygotes) as stronger smelling, and 2 chose the $H-2^{b}$ animals ( $b b$ homozygotes). Such disagreement was not unexpected, given that subjects identified one or the other strain on the basis of their internal criteria of "strength." That strength of odor was used as the stimulus dimension in the present experiments does not mean that it is the best descriptor or most salient stimulus dimension, only that strength made sense to the subjects as an instruction and provided significant results on discrimination tests.

These results appeared to indicate an ability of humans to distinguish mice by scent and encouraged us to perform several more experiments.

\section{Experiment 2}

Mice frequently sniff at feces and explore each other anogenitally. Goodrich, Gambali, and Redhead (1985) recently reported that a specialized odorous material is placed in mouse feces during marking and defecation. To determine whether mouse fecal pellets contain cues sufficient to enable the discrimination of strain, we used pellets as odor sources in this experiment.

To obtain data comparable across subjects and strains, we adapted for our purposes the psychophysical method of magnitude estimation (Moskowitz, 1977), in which subjects produce their own quantitative sensory scale, which can then be compared with others.

The choice of mouse strains to serve as the odor sources in this experiment was based on genetic relatedness and major histocompatibility ( $\mathrm{H}-2$ ) type. Two unrelated strains ( $\mathrm{C} 57 \mathrm{BL} /$ 6 and $A K R$ ) and two different $H-2$ alleles ( $b$ and $k$ ) were used in a $2 \times 2$ design. This allowed us to compare $H-2$ differences with strain held constant and to compare strain differences with $H-2$ type held constant.

\section{Method}

Dry fecal pellets were collected from individually housed male mice. Twelve animals were used, three from each of the following

Table 1

Number of Times Each H-2 Type Was Chosen as "Stronger" Smelling in Experiment I, With Whole-Body Odor of Mouse Strains C57BL/6 and C57BL/6-H-2 ${ }^{k}$ as Stimuli

\begin{tabular}{ccc}
\hline & \multicolumn{2}{c}{$H-2$ typc } \\
\cline { 2 - 3 } Subject & $k k$ & $b b$ \\
\hline 1 & 21 & $4^{*}$ \\
2 & 19 & $6^{*}$ \\
3 & 7 & $18^{*}$ \\
4 & 4 & $21^{*}$ \\
5 & 19 & $6^{*}$ \\
6 & 11 & 14 \\
7 & 13 & 12 \\
\hline
\end{tabular}

${ }^{*} p<.05$. strains: C57BL/6-H-2k C57BL/6 $\left(H-2^{\mathrm{b}}\right), \mathrm{AKR}-I I-2^{\mathrm{b}}$, and AKR $(I I-$ $\left.2^{\mathrm{k}}\right)$. Pellets $(0.6-0.7 \mathrm{~g})$ were cleaned of bedding material and placed in borosilicate culture tubes $(10 \times 75 \mathrm{~mm})$, which were wrapped in white adhesive paper.

Thirteen subjects were presented with each sample tube three times in randomized order ( 36 trials total) and asked to assign each tube a number, reflecting how strongly it smelled. Larger numbers indicated stronger odor: there was no upper limit to the scale; zeroes could be used if no odor was perceived. Subject and experimenter sat on opposite sides of an opaque partition, to avoid bias from facial cues. Subjects set their own pace, and intertrial intervals usually approximated $20 \mathrm{~s}$.

The 36 ratings of each subject were multiplicd by a factor that standardized the mean of the ratings to 100 . From these transformed ratings, a mean score was calculated for each mouse strain. The four mean strain scores for each subject were compared in a two-way analysis of variance (ANOVA).

\section{Results and Discussion}

The data are summarized in Table 2 . There were significant effects of genetic background, $F(1,48)=9.08, p<.01$, and of $I I-2$ type, $F(1,48)=8.10, p<.01$. The interaction term was not significant. These results indicate that the feces of male C57BL/6 mice smelled stronger than those of AKR males regardless of $H-2$ type and that $k k$ homozygous male mice smelled stronger than $b b$ homozygous males regardless of strain. Differences between $H-2$ types were larger for the AKR strain.

Although fecal pellets contained cues sufficient to allow olfactory discrimination, we cannot determine from these data whether the odor source was (a) the feces themselves, (b) material secreted onto the feces from an anal gland (Goodrich et al., 1985), or (c) contamination of the feces by urine.

\section{Experiment 3}

In Experiment 2, human subjects were able to discriminate, by olfaction, between dry feces of male mice from different strains and $H-2$ types. It is known anecdotally that male mice smell stronger than females. One way $H-2$ type might influence odor production is through effects on steroid metabolism (Ivânyi, Hampl, Micková, \& Stárka. 1976). If this were the case, we might expect different results, using female mice as the odor source. To test this, we repeated Experiment 2, using female mice.

\section{Method}

The mouse strains and experimental procedures were identical to those of Experiment 2.

\section{Results and Discussion}

The data for the 12 subjects tested are summarized in Table 2 . There was a marginally significant interaction of strain and $H-2$ type, $F(1,44)=3.82, p=.057$, indicating that humans can discriminate the fecal odor of female mice.

Odor differences were strongest between $H-2$ types of the AKR strain, in which feces from $H-2^{k}$ females were judged to 
Table 2

Normalized Magnitude Estimates (Mean \pm SE) of Mouse Odors

\begin{tabular}{lccccc}
\hline & & $\begin{array}{c}\text { Exp. 2: } \\
\text { Male } \\
\text { feces }\end{array}$ & $\begin{array}{c}\text { Exp. 3: } \\
\text { Female } \\
\text { feces }\end{array}$ & $\begin{array}{c}\text { Exp. 4: } \\
\text { Male } \\
\text { urine }\end{array}$ & $\begin{array}{c}\text { Exp. 5: } \\
\text { Male } \\
\text { urine }\end{array}$ \\
\hline C57BL/6 & $b b$ & $106 \pm 7$ & $99 \pm 5$ & $90 \pm 3$ & - \\
C57BL/6- $H-2^{k}$ & $k k$ & $113 \pm 6$ & $94 \pm 6$ & $110 \pm 3$ & - \\
AKR-H-2 & $b b$ & $75 \pm 7$ & $91 \pm 11$ & - & $92 \pm 4$ \\
AKR & $k k$ & $105 \pm 5$ & $114 \pm 7$ & - & $108 \pm 4$ \\
\hline
\end{tabular}

Note. In each experiment, the estimated magnitudes assigned to the mouse odors by each human subject were normalized to an overall mean of 100 .

be stronger smelling than those from $H-2^{\text {b }}$ females. This result was consistent with those of Experiment 2 with male mice.

\section{Experiment 4}

Mice scent mark their environment with urine, and their urine is known to contain chemical cues sufficient to enable $H$-2 discrimination by other mice (Yamaguchi et al., 1981). In Experiments 4 and 5, we asked whether humans can discriminate $H$-2 type, using male mouse urine as an odor source. The $H-2$ types were the same as in Experiment $2(b b$ and $k k$ ), but each background strain was tested separately (C57BL/6 in Experiment 4 and AKR in Experiment 5). Magnitude estimation was again used to obtain ratings of odor strength.

\section{Method}

Three males each of the C57BL/6 $\left(H-2^{b}\right)$ and C57BL/6- $H-2^{k}$ strains served as urine donors. Urine $(0.2-0.3 \mathrm{ml})$ was collected overnight in metabolism cages and tested the following day. Urine from each male was presented in a separate $10 \times 75 \mathrm{~mm}$ borosilicate culture tube wrapped in white adhesive paper. Samples were coded, and the experiment was run double blind. The 18 ratings generated by each subject were transformed by a procedure analogous to that used in Experiments 2 and 3. Transformed ratings were collapsed across mouse strains and analyzed by ANOVA. Sixteen subjects participated.

\section{Results and Discussion}

The urines of $\mathrm{C} 57 \mathrm{BL} / 6$ and $\mathrm{C} 57 \mathrm{BL} / 6-\mathrm{H}-2^{\mathrm{k}}$ male mice received significantly different ratings of perceived strength, repeated measures ANOVA, $F(1,15)=8.83, p<.01$ (Table 2). The $H-2^{\mathrm{k}}$ mice were rated stronger smelling than the $H-2^{\mathrm{b}}$ mice.

\section{Experiment 5}

In Experiment 4, $b b$ and $k k H-2$ types were found to be discriminable against the genetic background of the C57BL/ 6 strain when male urine was the odor source. In this experiment we asked whether these same $H$-2 types were discriminable against the background of the AKR strain. Again male urine was the odor source.

\section{Method}

The experimental design and statistical analysis were identical to those of Experiment 4, but the urine was collected from three males each of the AKR-H-2 $2^{\mathrm{b}}$ and AKR $\left(H-2^{\mathrm{k}}\right)$ strains. In a slight change of procedure, the urine was frozen the morning after collection in metabolism cages and stored for 12 weeks. The samples were brought to room temperature immediately before the experiment. As in Experiment 4, samples were coded, and the experiment was run double blind. Fifteen subjects participated.

\section{Results and Discussion}

Urine from males of the AKR-H-2 ${ }^{\mathrm{b}}$ and AKR strains received significantly different ratings, $F(1,14)=4.70, p<$ .05 (Table 2). The $H-2^{\mathrm{k}}$ genotype was perceived as smelling stronger than the $H-2^{\mathrm{b}}$ genotype, as was the case when these two $H-2$ types were compared in the C57BL/6 strain in Experiment 4.

\section{General Discussion}

The congenic lines of inbred mice used in this study differed only in the genetic loci on chromosome 17 that code for the major histocompatibility complex (Boyse, 1977). Human subjects were able to discriminate the whole-body odor of male mice from two congenic strains. Dry fecal pellets provided olfactory cues sufficient for subjects to discriminate between the males of two strains of mice differing at many genetic loci (AKR and C57BL/6) as well as between $I T-2$ types ( $b b$ and $k k$ ) within each strain. A similar result was obtained when feces from females of the two strains were used as odor sources. Finally, urine alone was a sufficient odor source to allow the discrimination of the $b b$ and $k k H-2$ phenotype against the genetic background of both the C57BL/6 and AKR strains. In six of the seven comparisons of $\mathrm{H}-2$ type within strains, the $k k$ homozygous animals were rated as stronger smelling.

The research of Whitten (1973) and of Lyon and Hawkes (1970) indicates that strong odor in mice is androgen dependent. We did not test males and females simultaneously in a single experiment and so cannot compare relative odor strength of the sexes. However, our subjects could discriminate strain and $H-2$ type with female feces as the odor source (Experiment 3).

These results provide an empirical, quantitative basis for previous anecdotal reports of human-detectable odor differences among mouse strains (Keeler, 1968). In particular, they lend support to Whitten's (1973) claim that he could perceive intensity differences among urine samples of male BALB/c, SJL, 129, C57BL/10, and AKR strain mice.

The odor differences found in these inbred lines of $\mathrm{H}-2$ congenic mice may have a biological significance in themselves. The MHC, a set of genes found in all vertebrates, is critically involved in immunological recognition of foreign cells (antigens). Thomas (1975) drew attention to the functional analogy between the olfactory and the immune systems, both of which can respond to a vast range of chemical information from the environment. Mate choice in some congenic strains of mice has been shown to be influenced by $\mathrm{H}-2$ type, presumably based on distinctive odors associated 
with specific $H-2$ types (Yamazaki et al., 1979). It has been proposed (Yamazaki et al., 1976) that outbreeding based on $H-2$ dissimilar mating biases provides a selective advantage because $H-2$ heterozygous offspring can produce a wider range of antibodies than homozygotes. Lenington (in press; Lenington \& Egid, 1985) showed that mate choice in wild Mus musculus is correlated with genotype at the $T$-locus, which is located near the $\mathrm{H}-2$ locus and which is also associated with the production of characteristic odors. Relatedly, it has been shown that MHC monomorphism in the cheetah (Acinonyx juhatus jubatus), perhaps due to a severe population bottleneck in its recent past, is associated with increased susceptibility to pathological viruses (O'Brien et al., 1985).

That rats (Beauchamp et al., 1985) and humans as well as mice can detect odor differences in these $H-2$ congenic mice raises the possibility that excreted metabolites with characteristic odors may have predated the evolution of an adaptive function for these odors in social communication. MHC diversity is correlated with diversity in many anatomical structures and physiological responses, and it would not be surprising if it also was correlated with diversity in excreted volatile metabolites (Beauchamp, Gilbert, Yamazaki, \& Boyse, in press).

In this regard, the source of perceivable $H$-2-associated differences in fecal odors poses an interesting question. Because all animals received the same laboratory chow, dietrelated differences in odor production can be ruled out. Mouse strains differ in the species of indigenous lactobacilli that inhabit their digestive tracts (Itoh, Mitsuoka, Sudo, \& Suzuki, 1983), and bacteria-based odors could be involved. The odors could also be the product of specialized anal scent glands, as recently proposed by Goodrich et al. (1985). Such glands are common in carnivores, and it has been argued that anal gland secretions may serve a scent-marking function (Macdonald, 1980).

Dry fecal pellets may have a practical advantage over urine samples for odor studies. Urine takes on extraneous odors after a few hours at room temperature. This restricts the time available for testing and the number of subjects that can be tested with a given sample. There appear to be no such limitations with dry fecal pellets. Indeed, ancient coprolites have proved useful in the odor and gas-chromatographic analysis of prehistoric diets (Moore, Krotoszynski, \& O'Neill, 1984).

\section{References}

Beauchamp, G. K.. Gilbert. A. N., Yamazaki, K.. \& Boyse, E. A. (in press). Genetic basis for individual discriminations: The major histocompatibility complex of the mouse. In D. Duvall, D. MüllerSchwarze. \& R. M. Silverstein (Eds.), Chemical signals in vertebrates: Vol. IV. Fololog!, evolution, and comparative biology. New York: Plenum Press.

Beauchamp, G. K., Yamazaki, K., Wysocki, C. J., Slotnick, B. M., Thomas, L., \& Boyse, E. A. (1985). Chemosensory recognition of mousc major histocompatibility types by another species. Proceedings of the National Academy of Sciences of the United State's of America, 82, 4186-4188.

Boyse. E. A. (1977). The increasing value of congenic mice in biomedical research. Laboratory Animal Scienc'c. 27, 771-781.

Doty, R. L., \& Dunbar, I. (1974) Color, odor. consistency, and secretion rate of anal sac secretions from male. female, and earlyandrogenized female beagles. American Joumal of ' 'eterinary $R e^{-}$ search, 35, 729-731.

Goodrich, B. S., Gambali, S., \& Redhead, T. (1985, July). Behavioural function and chemistry of volatiles from faeces of housc mice. Paper presented at the Fourth International Conference on Chemical Signals in Vertebrates, Laramie, WY.

Itoh, K., Mitsuoka, T., Sudo, K., \& Suzuki, K. (1983). Comparison of fecal lactobacilli in mice of different strains under different housing conditions. l'ersuchsticrkunde, 25, 193-200.

Iványi, P., Hampl, R., Micková, M., \& Stárka, L. (1976). The influence of the $\mathrm{H}-2$ system on blood serum testosterone level. Folia Biologica, 22, 42-43.

Keeler, C. (1968). Note on olfacto-genes. Journal of Heredit,, 59, 208.

Klcin. J. (1982). Immunology: The science of self-nonself discrimination. New York: Wiley-Interscience.

Lenington, S. (in press). Phenotypic correlates of T-locus genotype in wild house mice: Implications for evolutionary models. In B. Komisaruk \& H. Siegel (Eds.), Interdisciplinary aspects of behavior: J. S. Rosenblatt Festschrift.

Lenington, S., \& Egid, K. (1985). Female discrimination of male odors correlated with male genotype of the $T$ locus: A response to T-locus or H-2-locus variability? Behavior Genetics, 15, 53-67.

Lyon, M. F., \& Hawkes. S. G. (1970). X-linked gene for testicular feminization in the mouse. Nature, 227, 1217-1219.

Macdonald, D. W. (1980). Patterns of scent marking with urine and faeces amongst carnivore communities. Slmposia of the Zoological Society of London, 45, 107-139.

Moore, J. G., Krotoszynski, B. K., \& O'Neill, H. J. (1984). Fecal odorgrams: A method for partial reconstruction of ancient and modern diets. Digestive Diseases and Sciences, 29, 907-911.

Moskowitz, H. R. (1977). Psychophysical and psychometric approaches to sensory evaluation. Critical Revien's in Food Science and Nutrition, 8, 41-79.

O'Brien. S. J., Roelke, M. E.. Marker, L.. Newman, A., Winkler, C. A., Meltzer, D., Colly, L., Evermann, J. F., Bush, M.. \& Wildt, D. E. (1985). Genctic basis for species vulncrability in the cheetah. Science, 227, 1428-1434.

Smith, W. J. (1977). The behavior of communicating. Cambridge, MA: Harvard University Press.

Thomas, L. (1975). Symbiosis as an immunologic problem. In F. Neter \& F. Milgrom (Eds.). The immune system and infectious discases (Fourth International Convocation of Immunology, pp. 2-11). Basel: Karger.

Whitten. W. K. (1973). Genctic variation of olfactory function in reproduction. Journal of Reproduction and Fertility (Suppl.), 19, 405-410.

Yamaguchi. M.. Yamazaki, K.. Beauchamp, G. K., Bard, J., Thomas, L., \& Boyse, E. A. (1981). Distinctive urinary odors governed by the major histocompatibility locus of the mouse. Proceedings of the National Academy of Sciences of the United Siates of America, $78,5817-5820$.

Yamazaki, K.. Boyse. E. A., Miké, V., Thaler, H. T., Mathieson, B. J., Abbott. J., Boyse, J., Zayas, Z. A., \& Thomas, L. (1976). Control of mating preferences in mice by genes in the major histocompatibility complex. Journal of Experimental Medicine. 144, 1324 1335.

Yamazaki, K., Yamaguchi, M., Baranoski, L., Bard, J., Boyse, E. A., \& Thomas, L. (1979). Recognition among mice: Evidence from the use of a Y-maze differentially scented by congenic mice of different major histocompatibility types. Journal of Experimental Medicine, 150, 755-760.

Received September 24, 1985 Revision received February 22, 1986 